\title{
A COMPARATIVE STUDY OF EFFECT OF 0.5\% AND 0.75\% ISOBARIC ROPIVACAINE IN SPINAL ANAESTHESIA IN PATIENTS UNDERGOING ELECTIVE LOWER LIMB SURGERIES
}

\author{
Tridip Jyoti Borah ${ }^{1}$, Anulekha Chakrabartty22, Dipika Choudhury ${ }^{3}$ \\ ${ }^{1}$ Senior Resident Doctor, Department of Anaesthesiology and Critical Care, North Eastern Indira Gandhi Regional Institute of Health \\ and Medical Sciences, Shillong. \\ 2Professor, Department of Anaesthesiology and Critical Care, Gauhati Medical College and Hospital, Guwahati. \\ 3Professor, Department of Anaesthesiology and Critical Care, Gauhati Medical College and Hospital, Guwahati.
}

ABSTRACT
OBJECTIVES
The study was conducted to compare the differences in the onset, duration of action and complications of intrathecal isobaric
ropivacaine $0.5 \%$ (Group I) and intrathecal isobaric ropivacaine $0.75 \%$ (Group II) in elective lower limb surgeries.

\section{METHODS}

We enrolled 60 patients of ASA (American Society of Anaesthesiologists) Grade I-II scheduled for lower limb surgeries under spinal anaesthesia for this prospective randomized control trial. The patients were randomized to receive either $15 \mathrm{mg}$ of $0.5 \%$ isobaric ropivacaine or $22.5 \mathrm{mg}$ of $0.75 \%$ isobaric ropivacaine intrathecally. The time of onset of sensory and motor block, haemodynamic status, time for regression of sensory level to T10 dermatome, time of first request of analgesics and adverse effects were compared in both the groups.

\section{RESULTS}

The time of onset of sensory and motor block was significantly longer in Group-I than Group-II $(\mathrm{P}<0.001)$. Haemodynamic changes did not differ in patients of either group ( $\mathrm{P}>0.05)$. The onset of analgesia was faster in Group II $(2.13 \pm 0.50 \mathrm{mins}$.) than Group I (2.6 \pm 0.93 mins.). The time for regression of sensory level to T10 dermatome (Group-I $150 \pm 28.9$ minutes and Group-II $180 \pm 32.07)$ were statistically longer in Group II $(\mathrm{P}<0.001)$. The time of first request of analgesics by the patient in Group-I was $197 \pm 31.20$ minutes and in Group II was $219 \pm 31.66$ minutes, which was statistically significant $(\mathrm{P}<0.001)$. The onset of motor block was quicker $(\mathrm{P}<0.05)$ and the total duration of motor block was longer $(\mathrm{P}<0.05)$ in Group II. No unexpected adverse events were registered.

\section{CONCLUSION}

The subarachnoid injection of glucose-free isobaric ropivacaine $0.5 \%$ and $0.75 \%$ solutions results in a variable spread of analgesia, accompanied by a good quality of motor block. Ropivacaine $0.75 \%$ produces a better quality of analgesia and longer duration of analgesia than the $0.5 \%$ solution.

\section{KEYWORDS}

Intrathecal, Isobaric 0.5\% Ropivacaine, Isobaric 0.75\% Ropivacaine.

HOW TO CITE THIS ARTICLE: Borah TJ, Chakrabartty A, Choudhury D. A comparative study of effect of $0.5 \%$ and $0.75 \%$ isobaric ropivacaine in spinal anaesthesia in patients undergoing elective lower limb surgeries. J. Evolution Med. Dent. Sci. 2016;5(30):

1542-1547, DOI: $10.14260 /$ jemds/2016/363

\section{INTRODUCTION}

"Pain is a more terrible lord of mankind than death itself" Albert Schweitzer.

In pursuit of relief of pain, particularly relief of pain during and after surgery, many attempts have been made since time immemorial.

August Bier performed the first spinal anaesthesia more than a century ago by injecting cocaine into the CSF of a patient in $1898 .{ }^{1}$ More than a century has passed and even today it is one of the most popular techniques for both elective and emergency surgical procedures, particularly

Financial or Other, Competing Interest: None.

Submission 20-02-2015, Peer Review 18-03-2016,

Acceptance 23-03-2016, Published 13-04-2016.

Corresponding Author:

Dr. Tridip Jyoti Borah

Senior Resident Doctor,

Department of Anaesthesiology and Critical care,

NEIGRIHMS,

Shillong-793018.

E-mail: tridipborah2@gmail.com

DOI: $10.14260 /$ jemds $/ 2016 / 363$
Caesarean sections, lower abdominal surgeries, orthopaedic lower limb surgeries and urological surgeries just to name a few. ${ }^{2}$

When lignocaine was withdrawn from clinical practice for spinal anaesthesia because of transient neurological symptoms, bupivacaine hydrochloride has become established as the local anaesthetic of choice for most surgical procedures under spinal anaesthesia for many years. However, in an editorial, Dr. Albright reported six cases of sudden cardiovascular collapse immediately after presumed accidental intravascular injection of bupivacaine and etidocaine despite negative aspiration test and also postulated that cardiopulmonary resuscitation in contrast to lidocaine might be difficult, if not impossible. ${ }^{3}$ Ropivacaine was introduced into clinical practice in 1996 and has consistently demonstrated an improved safety profile over bupivacaine with a reduced CNS and cardiotoxic potential. Ropivacaine was approved for administration through the intrathecal route in the European Union in February 2004 and was introduced in India in 2009.4 It is a safe, reliable and inexpensive technique with the advantage of providing 
surgical anaesthesia and prolonged postoperative pain relief. It is also an effective treatment for operative pain and blunts autonomic, somatic and endocrine responses. ${ }^{5}$

Ropivacaine is a new amino-amide, local anaesthetic, structurally related to bupivacaine and mepivacaine. 6 A number of different doses of ropivacaine have been used for spinal anaesthesia and the dose-response relationship has not been fully determined. Although several studies have examined the effects of intrathecal Ropivacaine in both labouring women and patients undergoing minor surgery, few studies have evaluated its use in anaesthesia in major surgery.

This study was designed to investigate the safety and efficacy of two concentrations of intrathecal Ropivacaine $(0.5 \%$ and $0.75 \%)$ in patients undergoing elective lower limb surgeries.

\section{METHODS}

After approval from the Hospital Ethics Committee, this study was carried out on 60 patients of either sex between the ages of 18-50 years undergoing elective surgeries on lower limb from April 2012 to March 2013. Adult patients belonging to ASA class I and II without any comorbid diseases were included in the study. Patients who did not give consent, patients belonging to ASA class III, IV and V, patients with comorbid diseases like diabetes, hypertension and any other contraindications to spinal anaesthesia were excluded from the study. The patients after taking written and informed consent were divided randomly into two groups of 30 each. Group I patients received $3 \mathrm{~mL}$ isobaric $0.5 \%$ Ropivacaine $(15$ $\mathrm{mg}$ ) and Group II patients received $3 \mathrm{~mL}$ isobaric $0.75 \%$ Ropivacaine $(22.5 \mathrm{mg})$ intrathecally.

They were preloaded with Ringer's lactate solution 10 $\mathrm{mL} / \mathrm{kg}$ before initiation of the spinal block. The subarachnoid puncture was performed in sitting position with a 25-gauge Quincke spinal needle. The subarachnoid block was given by midline approach at the L3-4 interspace and study drug was given over 30 seconds based on the group. Immediately after intrathecal injection, patients were placed in supine position. An anaesthesiologist who was blinded regarding which local anaesthetic was used, assessed sensory and motor block after the intrathecal injection at 1 and 2 minutes and then subsequently at 2 minute intervals until surgical anaesthesia was achieved. The segmental level of sensory block to pin prick was evaluated bilaterally along the mid-clavicular line by using a short bevelled 27-gauge needle. The motor block of both legs was assessed using the modified Bromage scale ( $0=$ full movement, $1=$ unable to raise extended leg, $2=$ unable to flex knee, $3=$ no movement).

All the drugs used were preservative free. Baseline pulse, blood pressure and respiratory rate, $\mathrm{SpO} 2$ were recorded. Intraoperative monitoring consisted of pulse rate, BP, ECG (lead II), RR and Sp02. Surgery was started after establishment of surgical blockade up to T10 level. The readings of pulse rate, $\mathrm{SBP}, \mathrm{DBP}, \mathrm{SpO} 2$ and RR were taken at 2 min. intervals for first 20 minutes and after that at 10 minutes' interval till the end of surgery. Time for onset of sensory block, motor block, duration of sensory blockade up to T10, duration of complete motor blockade, duration of analgesia, any side effect and complaints, quality of anaesthesia and blood loss were recorded. Time for onset of sensory block was defined as time interval between the completion of injection of the study drug to the onset of complete loss of sensation to pin prick at the level of thoracic dermatome 10. Time for onset of complete motor block. It is the time taken for inability of the patient to move leg or feet. Hypotension was defined as fall in $\mathrm{SBP}<100 \mathrm{mmHg}$ or a fall in the mean arterial blood pressure more than $30 \%$ of the preoperative value. It was treated with a rapid infusion of crystalloids and if persisting a bolus of Inj. Mephentermine 6 mg was administered. Bradycardia was defined as fall in heart rate below 50/min. was treated with Inj. Atropine sulphate $0.6 \mathrm{mg}$ IV bolus. Visual analogue scale was used to quantify pain. Analgesics were given when patient complained of pain or VAS score was $\geq 4$.

Quality of surgical anaesthesia was assessed by the surgeon (Excellent: No complaints; Good: Minimal discomfort, relieved by assurance; Fair: Minimal pain, relieved by opioids; Poor: If large dose of opioids or GA required).

Postoperatively, vital parameters of the patients and regression of block were recorded. Postoperatively, patients were monitored at hourly intervals up to 2 hours, then 2 hourly intervals up to $8^{\text {th }}$ hour.

\section{RESULTS}

The patients studied across the group did not vary much with respect to age, sex, height, weight or ASA status (Table 1). The type of surgeries performed were almost identical in both the groups.

Heart rate and mean arterial pressure (Table 2 and 3) in both the groups did not vary significantly. Cardiovascular changes were unremarkable throughout and similar in the two groups, as were the volumes of fluid and blood administered.

The onset of sensory and motor blockade in Group-I was slower compared to Group-II, which was statistically highly significant $(\mathrm{P}<0.05)$. The duration of sensory anaesthesia at T10 dermatome in Group-I was shorter compared to Group-II which was statistically highly significant $(\mathrm{P}<0.05)$. The duration of motor blockade in Group-I was less than in Group-II, which was statistically highly significant $(\mathrm{P}<0.05)$ (Table 4$)$. The time of first request of analgesics in Group-II was significantly later than in Group I which was statistically highly significant $(\mathrm{P}<0.05)$; 8 patients had shivering in Group I as compared to 12 patients in Group II. Two patients in Group I and two patients in Group II had bradycardia. There were no incidences of postdural puncture headache, nausea, vomiting or neurological sequelae in either group. The quality of surgical anaesthesia with $15 \mathrm{mg}$ of $0.5 \%$ isobaric ropivacaine and $22.5 \mathrm{mg}$ of $0.75 \%$ isobaric ropivacaine in our study was satisfactory in all patients. It was excellent in 29 patients in $0.75 \%$ group and 28 patients in $0.5 \%$ group. One patient in $0.75 \%$ group and two patients in $0.5 \%$ group developed minimal discomfort, which was managed with assurance only. No patients were given supplemental opioids or were converted to general anaesthesia.

\begin{tabular}{|c|c|c|c|}
\hline Data & Grp I & Grp II & P- Value \\
\hline Age (yrs.) & $36.36 \pm 8.32$ & $37.4 \pm 8.35$ & $>0.05$ \\
\hline Height (cms) & $160.13 \pm 4.58$ & $159.36 \pm 4.95$ & $>0.05$ \\
\hline Weight (kg) & $60.33 \pm 6.14$ & $60 \pm 6.57$ & $>0.05$ \\
\hline Sex (M/F) & $19 / 11$ & $20 / 10$ & $>0.05$ \\
\hline ASA grade(I/II) & $24 / 6$ & $24 / 6$ & $>0.05$ \\
\hline \multicolumn{4}{|c|}{ Table 1: Demographic Profile } \\
\hline
\end{tabular}




\begin{tabular}{|c|c|c|c|c|c|}
\hline \multirow{2}{*}{ TIME INTERVAL } & \multicolumn{2}{|c|}{ GROUP I } & \multicolumn{2}{c|}{ GROUP II } & P VALUE \\
\cline { 2 - 6 } & MEAN \pm SD & CHANGE & MEAN \pm SD & CHANGE & \\
\hline PREOPERATIVE & $91.60 \pm 5.06$ & & $93.31 \pm 4.95$ & -4.02 & $>0.05$ \\
\hline 2 MIN & $87.36 \pm 4.17$ & -4.24 & $89.29 \pm 5.70$ & -7.64 & $>0.05$ \\
\hline 4 MIN & $84.03 \pm 3.89$ & -7.57 & $85.67 \pm 4.54$ & -9.48 & $>0.05$ \\
\hline 6 MIN & $81.89 \pm 3.49$ & -9.70 & $83.83 \pm 5.34$ & -12.93 & $>0.05$ \\
\hline 8 MIN & $79.47 \pm 3.61$ & -12.13 & $80.38 \pm 5.34$ & -16.82 & $>0.05$ \\
\hline 10 MIN & $77.69 \pm 3.00$ & -13.91 & $76.49 \pm 3.32$ & -17.05 & $>0.05$ \\
\hline 12 MIN & $77.62 \pm 3.06$ & -13.98 & $76.26 \pm 3.50$ & -12.62 & $>0.05$ \\
\hline 14 MIN & $79.85 \pm 3.59$ & -11.75 & $80.69 \pm 3.00$ & -11.32 & $>0.05$ \\
\hline 16 MIN & $80.96 \pm 4.24$ & -10.64 & $81.99 \pm 4.31$ & -9.04 & $>0.05$ \\
\hline 18 MIN & $82.74 \pm 5.49$ & -8.86 & $84.27 \pm 3.99$ & -8.94 & $>0.05$ \\
\hline 20 MIN & $83.67 \pm 4.66$ & -7.93 & $84.37 \pm 4.22$ & -3.2 & $>0.05$ \\
\hline 30 MIN & $88.29 \pm 4.08$ & -3.31 & $90.11 \pm 6.40$ & -1.09 & $>0.05$ \\
\hline 40 MIN & $90.16 \pm 3.99$ & -1.44 & $92.22 \pm 5.82$ & -1.09 & $>0.05$ \\
\hline 50 MIN & $90.34 \pm 3.22$ & -1.26 & $91.18 \pm 6.15$ & -2.13 & $>0.05$ \\
\hline 60 MIN & $91.31 \pm 3.70$ & -0.29 & $92.29 \pm 4.88$ & -1.02 & \\
\hline
\end{tabular}

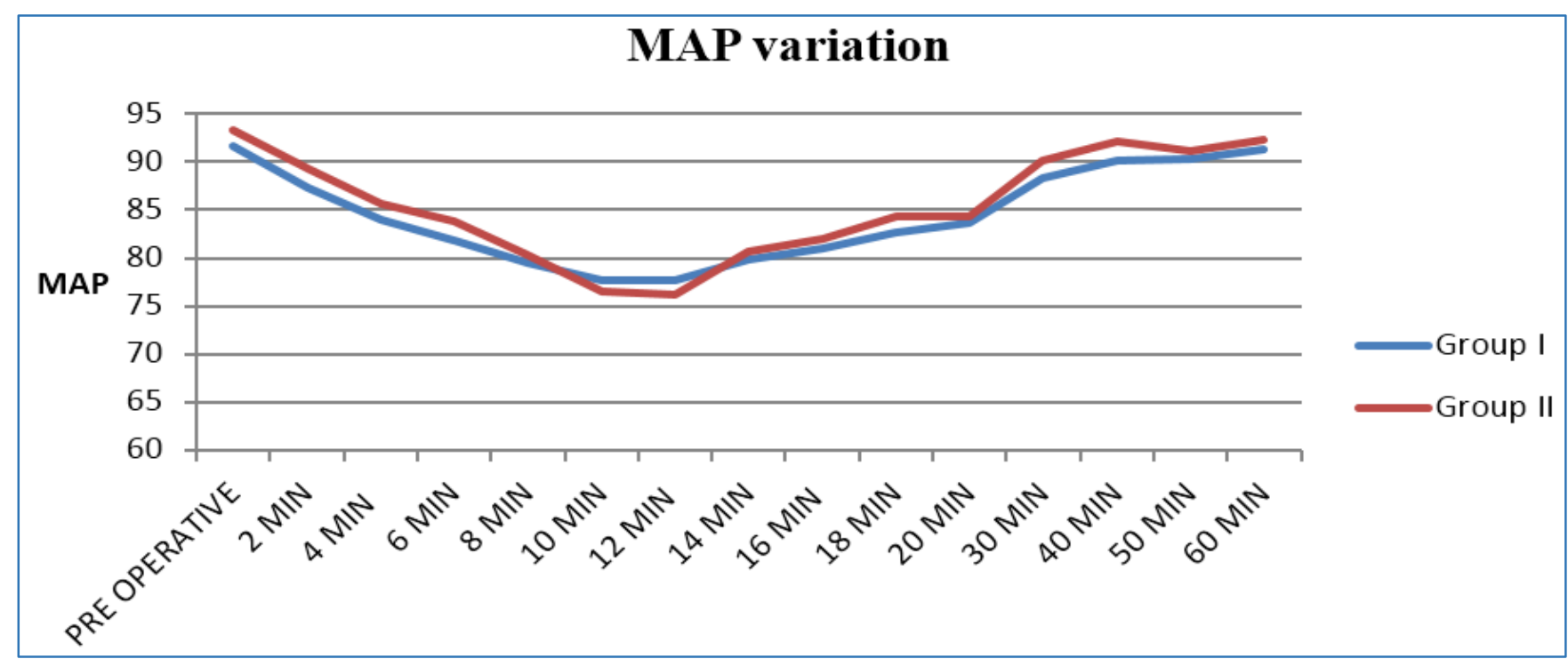

\begin{tabular}{|c|c|c|c|c|c|}
\hline \multirow{2}{*}{$\begin{array}{c}\text { TIME } \\
\text { INTERVAL }\end{array}$} & \multicolumn{2}{|c|}{ GROUP I } & \multicolumn{2}{|c|}{ GROUP II } & \multirow[t]{2}{*}{ P VALUE } \\
\hline & MEAN $\pm S D$ & CHANGE & MEAN $\pm S D$ & CHANGE & \\
\hline PREOPERATIVE & $87.86 \pm 5.06$ & & $86.73 \pm 3.54$ & & $>0.05$ \\
\hline $2 \mathrm{MIN}$ & $85.20 \pm 6.53$ & -2.66 & $86.06 \pm 5.98$ & -0.67 & $>0.05$ \\
\hline $4 \mathrm{MIN}$ & $87.53 \pm 5.16$ & -0.33 & $86.33 \pm 5.56$ & -0.40 & $>0.05$ \\
\hline $6 \mathrm{MIN}$ & $91.13 \pm 3.95$ & +3.27 & $89.53 \pm 4.62$ & +2.80 & $>0.05$ \\
\hline $8 \mathrm{MIN}$ & $92.33 \pm 4.52$ & +4.47 & $91.06 \pm 5.21$ & +4.33 & $>0.05$ \\
\hline $10 \mathrm{MIN}$ & $95.73 \pm 10.30$ & +7.87 & $94.93 \pm 4.63$ & +8.20 & $>0.05$ \\
\hline 12 MIN & $94.93 \pm 5.69$ & +7.07 & $92.96 \pm 13.10$ & +6.23 & $>0.05$ \\
\hline $14 \mathrm{MIN}$ & $94.06 \pm 4.31$ & +6.20 & $92.73 \pm 3.65$ & +6.00 & $>0.05$ \\
\hline 16 MIN & $92.93 \pm 3.92$ & +5.07 & $91.20 \pm 4.62$ & +4.47 & $>0.05$ \\
\hline 18 MIN & $91.46 \pm 5.48$ & +3.59 & $90.00 \pm 2.77$ & +3.27 & $>0.05$ \\
\hline $20 \mathrm{MIN}$ & $87.63 \pm 11.00$ & -0.23 & $87.13 \pm 2.90$ & +0.39 & $>0.05$ \\
\hline $30 \mathrm{MIN}$ & $82.66 \pm 6.37$ & -5.20 & $82.86 \pm 4.60$ & -3.87 & $>0.05$ \\
\hline 40 MIN & $82.8 \pm 5.18$ & -5.06 & $81.73 \pm 3.81$ & -5.00 & $>0.05$ \\
\hline $50 \mathrm{MIN}$ & $80.93 \pm 3.47$ & -6.93 & $81.73 \pm 4.02$ & -5.00 & $>0.05$ \\
\hline $60 \mathrm{MIN}$ & $81.13 \pm 2.30$ & -6.73 & $82.40 \pm 4.18$ & -4.33 & $>0.05$ \\
\hline
\end{tabular}




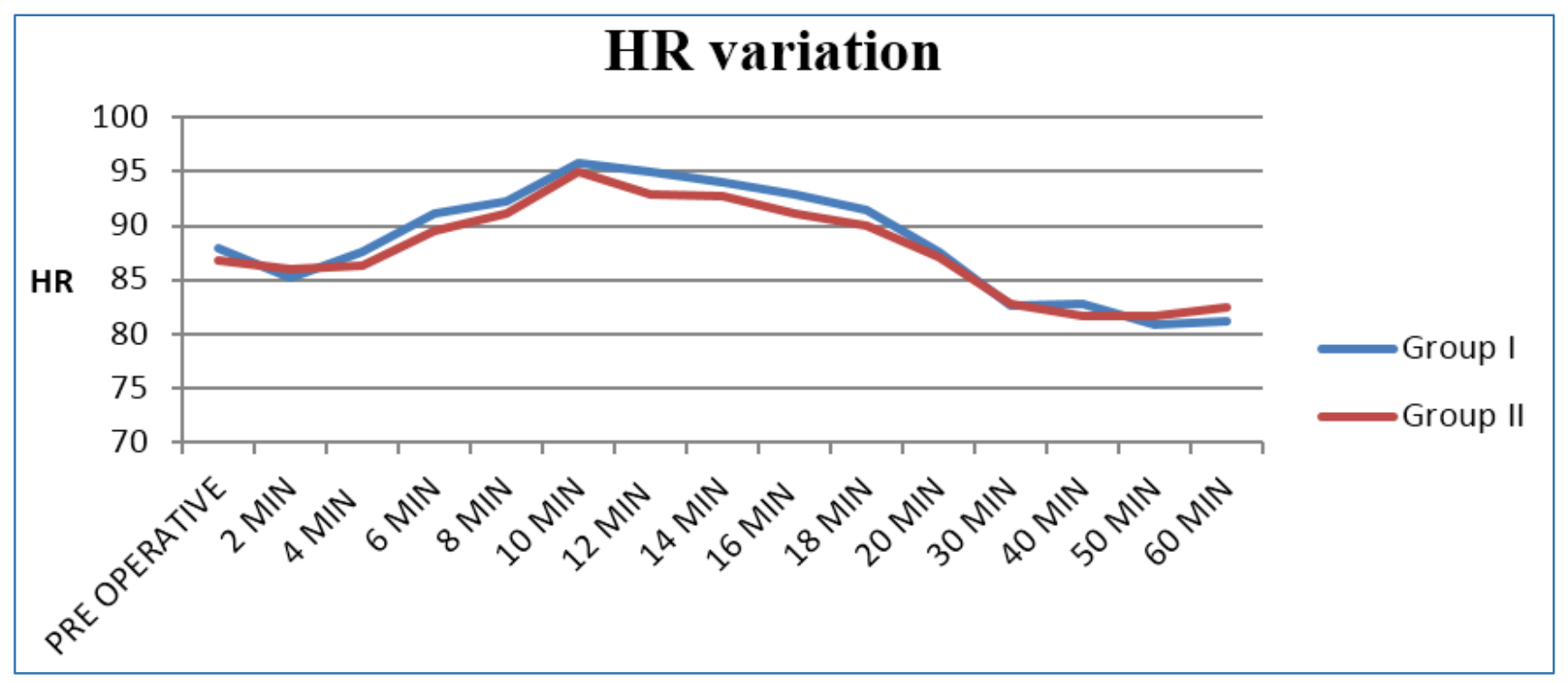

\begin{tabular}{|c|c|c|c|}
\hline Criteria & Group I & Group II & P Value \\
\hline \multicolumn{4}{|l|}{$\begin{array}{l}\text { SENSORY } \\
\text { BLOCK }\end{array}$} \\
\hline Onset & $2.6 \pm 0.93$ & $2.13 \pm 0.50$ & $<0.05$ \\
\hline $\begin{array}{c}\text { Time to max. } \\
\text { Cephalod spread }\end{array}$ & $12.83 \pm 3.64$ & $10.83 \pm 1.89$ & $<0.05$ \\
\hline Duration at T10 & $150 \pm 28.9$ & $180 \pm 32.07$ & $<0.05$ \\
\hline Total duration & $197 \pm 31.20$ & $219 \pm 31.66$ & $<0.05$ \\
\hline \multicolumn{4}{|l|}{ MOTOR BLOCK } \\
\hline Onset & $9.5 \pm 1.52$ & $8.16 \pm 2.45$ & $<0.05$ \\
\hline Total duration & $127 \pm 30.18$ & $142 \pm 27.21$ & $<0.05$ \\
\hline
\end{tabular}

\begin{tabular}{|c|c|c|c|}
\hline Side Effects & Grp I & Grp II & P Value \\
\hline Shivering & $8(26.67 \%)$ & $12(40 \%)$ & NS \\
\hline Hypotension & $5(16.67 \%)$ & $6(20 \%)$ & NS \\
\hline Nausea & 0 & 0 & \\
\hline Vomiting & 0 & 0 & \\
\hline Bradycardia & $2(6.67 \%)$ & $2(6.67 \%)$ & NS \\
\hline $\begin{array}{c}\text { Neurological } \\
\text { Sequelae }\end{array}$ & 0 & 0 & \\
\hline \multicolumn{4}{|l}{ Table 5: Comparison of Adverse Effects } \\
\hline
\end{tabular}

\section{DISCUSSION}

The purpose of our study was to compare the differences in the onset, duration of action and complications of intrathecal isobaric ropivacaine $0.5 \%$ (Group I) and intrathecal isobaric ropivacaine $0.75 \%$ (Group II) in elective lower limb surgeries. The haemodynamic findings in our study correlated with Jack W Van Kleef et al. in 1994, who in a similar study also found that the haemodynamic changes during induction of spinal anaesthesia were modest. ${ }^{7}$ Kim S Khaw et al (2001), also found that the incidence of hypotension was similar in a comparison of different doses of plain ropivacaine..$^{8} \mathrm{John}$ On-

Nin Wong et al. (2004), observed the same that there are no major cardiovascular changes in the two groups receiving plain ropivacaine in different doses compared to each other. ${ }^{9}$ P.D.W. Fettes et al. (2004), observed that cardiovascular changes were unremarkable in a comparison of plain and hyperbaric ropivacaine..$^{10}$ Helena Kallio et al. (2004) observed that the groups receiving plain ropivacaine did not have any differences in the haemodynamics after receiving different doses. ${ }^{11}$ From the above studies, we can conclude that use of either $15 \mathrm{mg}$ or $22.5 \mathrm{mg}$ of plain ropivacaine intrathecally causes no gross haemodynamic disturbances.

In our study, the onset of sensory blockade in group-I was $2.6 \pm 0.93$ minutes compared to $2.13 \pm 0.50$ minutes groupII which was statistically highly significant $(\mathrm{P}<0.05)$. Similarly, the onset of motor blockade in Group-I was also slower $(9.5 \pm 1.52$ minutes) compared to $8.16 \pm 2.45$ minutes in Group-II, which was also statistically highly significant $(\mathrm{P}<0.05)$.

The median time to reach the highest level of analgesia was less than $15 \mathrm{~min}$. in both groups (Ropivacaine 0.5\% group, $12.83 \pm 3.64$ min.; ropivacaine $0.75 \%$ group $(10.83 \pm 1.89 \mathrm{~min})$. Our results were similar to Wahedi et al. (1996) who in their study observed that duration of analgesia as well as duration and degree of motor block increases with the higher concentration. ${ }^{12}$ John On-Nin Wong et al. in 2004, opined that the onset of sensory and motor block were similar in two groups of ropivacaine $0.75 \%$, but different doses. ${ }^{9}$ Ying Y. Lee et al. in 2007 found that the onset of motor blockade was more reliable with the $0.75 \%$ ropivacaine. ${ }^{13}$ Engin Erturk et al. (2009) compared $12 \mathrm{mg}$ ropivacaine and 8 mg bupivacaine in spinal anaesthesia for major orthopaedic surgery in geriatric patients and found the onset time of sensory block to be $(8 \pm 1.2)$ minutes for ropivacaine, which is longer than our study. But they also used less amount of drug (12 mg) than our study. ${ }^{14}$ Surjeet Singh et al. (2012) while comparing intrathecal $0.75 \%$ isobaric ropivacaine versus $0.5 \%$ heavy bupivacaine for elective caesarean delivery concluded that adequate level of sensory analgesia and motor block was achieved in all patients before surgery and the time to achieve sensory block to T10 was similar to our study. 15 
In the present study, the duration of sensory anaesthesia at T10 dermatome in Group-I was $150 \pm 28.9$ minutes compared to $180 \pm 32.07$ minutes in Group-II, which was statistically highly significant. Jack W Van Kleef et al. in 1994, found that the duration of analgesia at the level of T12 was significantly longer in the $0.75 \%$ group as compared to $0.5 \%$ group. ${ }^{7}$ which correlates well with our findings. D. A. McNamee et al. (2001) compared $2.5 \mathrm{~mL}$ of $7.5 \mathrm{mg} / \mathrm{mL}$ and $2.5 \mathrm{~mL}$ of $10 \mathrm{mg} / \mathrm{mL}$ isobaric ropivacaine and found that the mean duration of sensory anaesthesia at T10 dermatome level was $3 \mathrm{hrs}$. in case of $7.5 \mathrm{mg} / \mathrm{mL}$ group, which correlates well with our observations. ${ }^{16}$ Engin Erturk et al. (2009) compared $12 \mathrm{mg}$ Ropivacaine and $8 \mathrm{mg}$ bupivacaine, in spinal anaesthesia for major orthopaedic surgery in geriatric patients and found the mean duration of sensory anaesthesia at T10 dermatome level was less than our study, but they also used less amount of drug (12 mg) than our study (15 mg and $22.5 \mathrm{mg}) .{ }^{14}$ Nuraycamgozeryilmaz et al. (2011) used $0.75 \%$ isobaric ropivacaine for caesarean section and found the time of sensory block regression to T10 to be $135 \pm 32.01$ mins., which was shorter than our study. This may be attributed to the fact that they used $15 \mathrm{mg}$ of ropivacaine as compared to $22.5 \mathrm{mg}$ of ropivacaine used in our study. ${ }^{17}$

In the present study, the duration of motor blockade in Group-I was $197 \pm 31.20$ minutes compared to $219 \pm 31.66$ minutes in Group-II, which was statistically highly significant. These findings of our study correlates well with Jack W Van Heef et al. 1994 who opined that the total duration of analgesia and motor blockade was longer in the $0.75 \%$ group. They observed that the greater propensity to produce a complete motor block and the longer duration of analgesia and motor block produced by the $0.75 \%$ ropivacaine solution, should be suitable for orthopaedic and vascular surgical procedures of intermediate duration, requiring an intense motor block.

The $0.5 \%$ ropivacaine solution on the other hand with its shorter duration of analgesia and often relatively moderate motor block of the lower limbs could be useful for transurethral procedures or minor orthopaedic surgery, where the degree of motor block is not of critical importance. ${ }^{7}$ Helena Kallio et al. in 2004, studied the effects of plain ropivacaine $20 \mathrm{mg}$ and $15 \mathrm{mg}$ and found that there was a significantly longer duration of motor block with $20 \mathrm{mg}$ than $15 \mathrm{mg}$ of ropivacaine.11 Engin Erturk et al. (2009) compared $12 \mathrm{mg}$ ropivacaine and $8 \mathrm{mg}$ bupivacaine, in spinal anaesthesia for major orthopaedic surgery in geriatric patients and found the total duration of motor block was less than our study, which may be attributed to the less amount of drug they used. ${ }^{14}$ Nuraycamgozeryilmaz et al. (2011) used $0.75 \%$ isobaric ropivacaine for caesarean section and found the total duration of motor block to be shorter than our study, but concluded that intrathecal plain ropivacaine with opioids might be superior to bupivacaine in terms of a longer sensory block and a shorter motor block duration for LSCS. ${ }^{17}$

In our study, the time of first request of analgesics in Group-I was $197 \pm 31.20$ minutes compared to $219 \pm 31.66$ minutes in Group-II, which was statistically highly significant $(\mathrm{P}<0.05)$, which was similar to what Kleef et al. found in 1994. The quality of surgical anaesthesia in our study was satisfactory in all patients. It was excellent in 29 patients in $0.75 \%$ group and 28 patients in $0.5 \%$ group. Our findings are consistent with the findings of D. A. McNamee et al. (2002) and Cemileoztin et al. (2007) who studied isobaric ropivacaine in total hip replacement and Caesarean delivery respectively.

\section{CONCLUSION}

The subarachnoid injection of glucose-free isobaric ropivacaine $0.5 \%$ and $0.75 \%$ solutions results in a variable spread of analgesia, accompanied by a good quality of motor block with minimal adverse effects. Ropivacaine $0.75 \%$ produces a better quality of analgesia and longer duration of analgesia than the $0.5 \%$ solution and thus reduces postoperative analgesic requirements. Isobaric $0.5 \%$ ropivacaine on the other hand provides a shorter duration of motor block and faster recovery. Thus, $0.75 \%$ ropivacaine offers a better quality of analgesia and a reliable motor block than $0.5 \%$ ropivacaine for elective lower limb surgery with haemodynamic stability.

\section{REFERENCES}

1. Parmeshwara G. Spinal, epidural to combined spinal epidural analgesia, the history of central neuraxial block. Indian J Anaesth 2001;45(6):406-412.

2. Dureja GP, Jayalaxmi TS. Colloid preloading before spinal and epidural anaesthesia. Hospital today 2000;11:601-603.

3. Albright GA. Cardiac arrest following regional anaesthesia with etidocaine or bupivacaine. Anaesthesiology 1979;51(4):285-7.

4. Wille M. Intrathecal use of ropivacaine: a review. Acta Anaesth Belg 2004;55(3):251-259.

5. David L Brown. Spinal, epidural and caudal anaesthesia. Miller's anaesthesia, churchhill livingstone, elsevier, 2010; $7_{\text {th }}^{\text {edn. }}$.

6. Akerman B, Hellberg B, Trossvik C. Primary evaluation of the local anaesthetic properties of the amino amide agent ropivacaine (LEA 103). Acta Anaesthesiol Scand 1988;32(7):571-8.

7. VanKleef JW, Veering BT, Burm AG. Spinal anesthesia with ropivacaine: a double blind study of efficacy and safety of $0.5 \%$ and $0.75 \%$ solutions in patients undergoing minor lower limb surgery. Anesth Analg 1994;78(6):1125-30.

8. Khaw KS, Ngan Kee WD, Wong EL, et al. Spinal ropivacaine for cesarean section: a dose-finding study. Anesthesiology 2001;95(6):1346-50.

9. John On-Nin Wong, Tan TD, Leung PO, et al. Comparison of the effect of two different doses of $0.75 \%$ glucose free ropivacaine for spinal anesthesia for lower limb and lower abdominal surgery. Kaohsiung J Med Sci 2004;20(9):423-30.

10. Fettes PDW, Hocking G, Peterson MK, et al. Comparison of plain and hyperbaric solutions of ropivacaine for spinal anaesthesia. Br J Anaesth 2005;94(1):107-11.

11. Kallio H, Snäll EV, Kero MP. Acomparison of intrathecal plain solutions containing ropivacaine 20 or $15 \mathrm{mg}$ versus bupivacaine $10 \mathrm{mg}$. Anesth Analg 2004;99(3):713-7.

12. Wahedi W, Nolte $H$, Klein P. Ropivacaine in spinal anaesthesia a dose-finding study. Anaesthesist 1996;45(8):737-744. 
13. Lee YY, Ngan Kee WD, Chang HK, et al. Spinal ropivacaine for lower limb surgery: a dose-response study. Anesth Analg 2007;105(2):520-3.

14. Erturk E, Tutuncu C, Eroglu A. Clinical comparison of 12 mg ropivacaine and $8 \mathrm{mg}$ bupivacaine, both with $20 \mathrm{ug}$ fentanyl, in spinal anaesthesia for major orthopaedic surgery in geriatric patients. Med Princ Pract 2010;19(2):142-147. DOI:10.1159/000249581

15. Surjeet Singh, Singh VP, Manish Jain, et al. Intrathecal $0.75 \%$ isobaric ropivacaine versus $0.5 \%$ heavy bupivacaine for elective cesarean delivery: a randomized controlled trial. J PAK MED STUD 2012;2(2). www.jpmsonline.com
16. Mc Namee DA, Mc Clelland AM, Scott S, et al. Spinal anaesthesia: comparison of plain ropivacaine $5 \mathrm{mg} \mathrm{ml}-1$ with bupivacaine $5 \mathrm{mg} \mathrm{ml}-1$ for major orthopaedic surgery. British Journal of Anaesthesia 2002;89(5):7026.

17. Nuray Camgoz Eryilmaz, Berrin Gunaydin. A comparison of the eff ects of intrathecalropivacaine and bupivacaine during cesarean section. Turk J Med Sci 2011;41(2):219-226. 